\title{
A novel estimate of the magnitude of heat produced in the rumen
}

\author{
BY J. W. CZERKAWSKI \\ Hannah Research Institute, Ayr KA6 ${ }_{5} H L$ \\ (Received 10 July 1979 - Accepted 25 September 1979)
}

Using a well-known equation relating the heat production to the respiratory measurements, the total heat produced in the animal is partitioned into heat produced in the rumen and heat produced in the body. It is shown that the values of the partition constants can be calculated by making two simple logical deductions. Consideration of known heats of fermentation of carbohydrate and protein shows that the deductions are justified.

It is well known that microbial activity is associated with heat production and under certain conditions this can be considerable. When expressed per unit weight, a micro-organism produces more heat than any other organism.

The heat produced by ruminant animals consists of the heat generated during reactions in the body of the animal and heat generated during fermentation in the gut, particularly the rumen. Total heat production can be measured directly or by using indirect calorimetric methods, but it is difficult to demonstrate how much of this heat is produced during fermentation in the rumen. The heat of fermentation has been determined in vitro using both indirect and direct methods (e.g. Marston, I948; Houpt, I968). If the composition of substrate and the nature of end-products of fermentation are known, it is possible to calculate the amount of heat produced from known stoichiometric relations. An attempt has been made to determine the amount of heat produced in the rumen by measuring changes in the temperature of blood supplying and leaving the rumen (Webster, 1978). This is subject to a great deal of error.

By writing equations for oxygen uptake and production of carbon dioxide during combustion of main dietary components (carbohydrate, protein, fat) it is possible to express the heat production as a function of $\mathrm{O}_{2}$ uptake and $\mathrm{CO}_{2}$ production, i.e. quantities that can be measured by simple respirometric methods. Such expressions, with corrections for methane and urinary protein, have been calculated by Brouwer (I958).

\section{Brouwer's equation}

Actually, Brouwer (I958) gives three equations (no. I4 in his paper), one to calculate heat production $(T)$ and two more equations to calculate the amounts of carbohydrate and fat metabolized ( $K$ and $F$ respectively). (Equation no. $I$ is the one that is most widely used and it has been updated (Brouwer, I965) by slight alteration of the constants. However, since the original paper forms the basis of the present argument, it will be better to use the equation as given originally.)

$$
\begin{aligned}
& T=3.869 \mathrm{O}_{2}+\mathrm{I} \cdot 195 \mathrm{CO}_{2}-0.227 P-0.5 \mathrm{I}_{5} \mathrm{CH}_{4}, \\
& K=-2.965 \mathrm{O}_{2}+4.170 \mathrm{CO}_{2}-0.390 P-\mathrm{I} \cdot 759 \mathrm{CH}_{4}, \\
& F=\mathrm{I} \cdot 7 \mathrm{I} 8 \mathrm{O}_{2}-\mathrm{I} \cdot 7 \mathrm{I} 8 \mathrm{CO}_{2}-0.315 P+\mathrm{I} \cdot 7 \mathrm{I} 8 \mathrm{CH}_{4},
\end{aligned}
$$

Where $\mathrm{O}_{2}, \mathrm{CO}_{2}$ and $\mathrm{CH}_{4}$ are the volumes (l) of oxygen utilized and carbon dioxide and methane produced respectively and $P$ is the amount $(\mathrm{g})$ of protein (nitrogen $\times 6.25$ ) excreted in urine. $T$ is given in kcal. 
The term 'metabolized' describes carbohydrate or fat oxidized completely to $\mathrm{CO}_{2}$ and water and not laid down in tissues. Using Brouwer's (1958) terminology and the energy values of dietary components as given in the paper, the heat produced is given by the third equation in the set of three simultaneous equations (Brouwer, 1958, p. I87) $\left(T=4 \cdot 2 K+9 \cdot 5 F+4 \cdot 4 P-9 \cdot 45 \mathrm{CH}_{4}\right)$. This means that $T$ is the heat produced when $K, F$ and $P$ g carbohydrate, fat and protein respectively are oxidized completely to $\mathrm{CO}_{2}$ minus the energy value of $\mathrm{CH}_{4}$.

\section{Partition of total heat into heat produced in the body and heat of fermentation}

Following some of the procedures published earlier by Forbes et al. (1927) and Krogh \& Schmit-Jensen (1920), Brouwer (1958) attempted to estimate the heat of fermentation by assuming that the $\mathrm{CO}_{2}$ that was formed during fermentation and the heat of fermentation were in constant proportion to the amount of methane formed. In the following discussion no assumption has been made about the relation between the heat of fermentation and methane production or any other reactions that take place in the rumen, although undoubtedly such relations exist. We state simply that provided the composition of the end-products of fermentation of carbohydrate or protein is constant the heats of fermentation of carbohydrate and protein are in constant proportions to the heats produced when these components of food are oxidized to $\mathrm{CO}_{2}$.

If $\mathrm{Kg}$ carbohydrate and $P \mathrm{~g}$ protein are burned to $\mathrm{CO}_{2}$, the heat produced will be $4.2 \mathrm{~K}$ and $4.4 P$ respectively (Brouwer, 1958). The proportions $\alpha$ and $\beta$ are defined as follows:

$$
\begin{aligned}
& \alpha=\frac{\text { heat of fermentation of I g carbohydrate }}{\text { heat of combustion of I g carbohydrate }}, \\
& \beta=\frac{\text { heat of fermentation of I } \mathrm{g} \text { protein }}{\text { heat of combustion of I g protein }}
\end{aligned}
$$

$T_{B}$ is defined as the heat produced in the body and $T_{F}$ as the heat produced during fermentation in the rumen and the caecum (heat of fermentation); together they account for total heat production $\left(T=T_{B}+T_{F}\right)$.

Thus, if all the carbohydrate and protein fermented is subsequently oxidized completely, the heat of fermentation is given in the following equation:

$$
T_{F}=4 \cdot 2 \alpha K+4 \cdot 4 \beta P \text {. }
$$

Since fat is not fermented in the rumen, there is no need for a 'fat' term in equation no. 6. If the values of $\alpha$ and $\beta$ are known, it is possible to calculate $T_{F}$ and $T_{B}$ in terms of amounts of carbohydrate and protein oxidized, or better, in terms of gases utilized and produced.

$T_{F}$ is obtained by substituting for $K$ from equation no. 2 in equation no. 6 and $T_{B}$ by subtracting from $T$ given in equation no. $I$.

$$
\begin{gathered}
T_{\mathrm{F}}=-\mathrm{I} 2.453 \alpha \mathrm{O}_{2}+\mathrm{I} 7.5 \mathrm{I} 4 \alpha \mathrm{CO}_{2}+(4.4 \beta-\mathrm{I} .638 \alpha) P-7.387 \alpha \mathrm{CH}_{4}, \\
T_{\mathrm{B}}=(3.869+\mathrm{I} 2.453 \alpha) \mathrm{O}_{2}+(\mathrm{I} \cdot 195-\mathrm{I} 7.5 \mathrm{I} 4 \alpha) \mathrm{CO}_{2} \\
+(-0.227+\mathrm{I} \cdot 638 \alpha-4.4 \beta)+(-0.5 \mathrm{I} 5+7.387 \alpha) \mathrm{CH}_{4} .
\end{gathered}
$$

\section{Possibility of estimating and calculating $\alpha$ and $\beta$}

It is possible to estimate the values of $\alpha$ and $\beta$ from known biochemical pathways, to define the coefficients in equations nos. 7 and 8 and thus to partition the total heat production. Webster (1978) in a review of the subject gives the heat of fermentation of starch as $6.4 \%$ of the heat of combustion of this compound, while direct determinations in the rumen give values ranging from $6-8 \%$ of heat of combustion of carbohydrate fermented. Webster (1978) also assumed that the heat of fermentation of protein was $3.4 \%$ of its energy value.

Various calculations from known stoichiometric relations and ATP yields show that the 
heat of fermentation of carbohydrates is within $6 \cdot 6-7.6 \%$ of their heat of combustion and that the heat of fermentation of dietary amino acids is unlikely to be less than $2.2 \%$ of their heat of combustion. The best estimates of the values of $\alpha$ and $\beta$ appear to be 0.070 and 0.028 respectively.

It is also possible to calculate $\alpha$ and $\beta$ on the basis of logical arguments. It is unlikely that the heat produced in the body will be influenced in any way by the amount of $\mathrm{CH}_{4}$ produced, since the latter is not oxidized. Since in general $\mathrm{CH}_{4}$ is not zero the contribution of the $\mathrm{CH}_{4}$ term will be minimal in equation no. 8 if the coefficient of $\mathrm{CH}_{4}$ approaches zero.

$$
7.387 \alpha-0.515=0
$$

The heat of fermentation $\left(T_{F}\right)$ depends primarily upon the amount of food converted to end-products and not on what happens to these end-products in the body. Provided that $\mathbf{N}$ is not limiting, it is unlikely that heat of fermentation in the rumen will be influenced by the amount of protein excreted by the host animals. The contribution of the $P$ term in equation no. 7 will be minimal when the coefficient of $P$ disappears.

$$
4.4 \beta-\mathrm{I} \cdot 638 \alpha=0 .
$$

Equations nos. 9 and to give $\alpha=0.0697$ and $\beta=0.0259$ which are very similar to the values estimated from stoichiometric relations earlier. We can substitute these values of $\alpha$ and $\beta$ in equation nos. 6,7 and 8 and obtain the following:

$$
T_{F}=0.290 K+0.114 P,
$$

or in terms of 'respiration' values:

$$
\begin{gathered}
T_{F}=\mathrm{I} \cdot 220 \mathrm{CO}_{2}-0.868 \mathrm{O}_{2}-0.5 \mathrm{I}_{5} \mathrm{CH}_{4}, \\
T_{B}=4.737 \mathrm{O}_{2}-0.026 \mathrm{CO}_{2}-0.227 P .
\end{gathered}
$$

\section{Some values and consequences}

It is instructive to express the heat of fermentation $\left(T_{F}\right)$ as proportion of total heat produced using equation no. II and the definition of $T$ and to consider two extreme instances.

$$
\frac{T_{F}}{T}=\frac{0.290 K+0.114 P}{4.2 K+9.5 F+4.4 P-9.45 \mathrm{CH}_{4}} .
$$

(I) Only carbohydrate is oxidized completely to $\mathrm{CO}_{2}$, protein and fat are laid down in tissues. Under these conditions $F=P=0 . \mathrm{CH}_{4}$ production from carbohydrate is known to differ with fermentation pattern (Demeyer \& Van Nevel, 1975), but if we assume the usual fermentation pattern of acetate-propionate-butyrate is $65: 20: 15$, then I $g$ carbohydrate would result in production of $0.06221 \mathrm{CH}_{4}$ (Czerkawski, 1978) and equation no. 14 gives $T_{F} / T=0.0802 ;$ (2) neither carbohydrate nor fat is oxidized completely to $\mathrm{CO}_{2}$. Here $K=F=0$ and since metabolism of protein results in production of $0.03551 \mathrm{CH}_{4} / \mathrm{g}$ (Blaxter \& Martin, 1962), equation no. 14 gives $T_{F} / T=0.028$.

It is possible to draw the following conclusions: $(a)$ it is unlikely that the heat of fermentation would be greater than $8 \%$ of the total heat produced; $(b)$ under normal conditions with fat and protein in the diet the heat of fermentation should be within 3-8\% of the total heat production; $(c)$ addition of a large proportion of fat will decrease $K$ and $P$ (numerator) and will increase the $F$ term in the denominator. If this is accompanied by inhibition of $\mathrm{CH}_{4}$ production, the denominator will be increased further. For instance, if the relative amounts of carbohydrate, protein and fat oxidized are 70,20 and, $10 \%$ respectively, this would give $T_{F} / T=0.047$ when there is no $\mathrm{CH}_{4}$ produced.

Some of our experimental results were used to calculate heats of fermentation in Tables I and 2. It can be seen in Table I that the heat of fermentation may account for $7 \cdot 2 \%$ of total heat produced or nearly $4 \%$ of gross energy intake and that the value for heat of fermenta- 
Table. 1. Calculation of heat of fermentation in sheep from calorimetric results (Czerkawski et al. 1966)

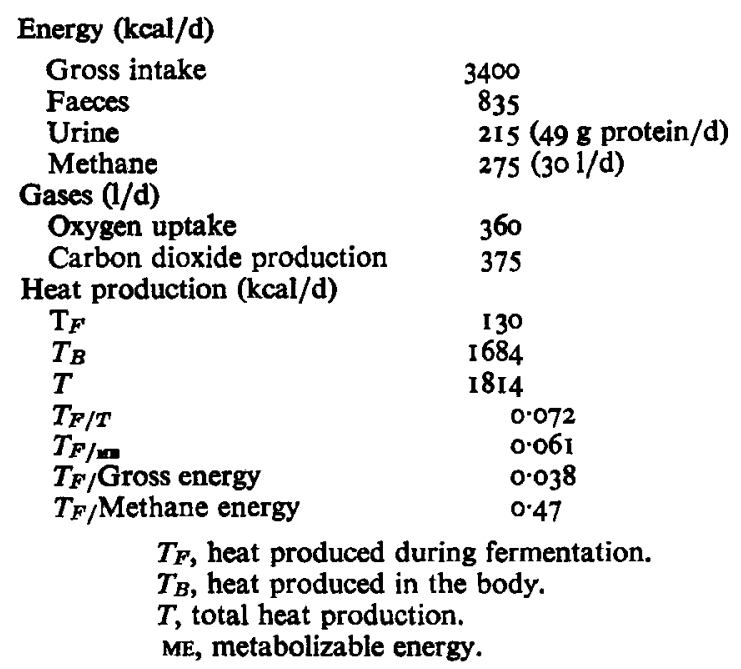

Table 2. Calculation of distribution of heat production in sheep from calorimetric values; effect of addition of propanediol (Clapperton \& Czerkawski, 1972) and addition of versatic acids (Clapperton \& Czerkawski, 1971) to the basal rations

\begin{tabular}{|c|c|c|c|c|}
\hline \multirow[b]{2}{*}{$\begin{array}{c}\text { Respiratory } \\
\text { exchanges }(\mathrm{d} / \mathrm{d})\end{array}$} & \multicolumn{2}{|c|}{ Expt I } & \multicolumn{2}{|c|}{ Expt 2} \\
\hline & Control & $\begin{array}{c}\text { Propanediol } \\
\text { infusion }\end{array}$ & Control & $\begin{array}{l}\text { Incorpor- } \\
\text { ation of } \\
\text { versatic } \\
\text { acids }\end{array}$ \\
\hline $\begin{array}{l}\text { Carbon dioxide } \\
\text { production }\end{array}$ & 364 & 399 & 393 & 392 \\
\hline Oxygen uptake & 359 & 408 & 365 & 376 \\
\hline Methane production & $24 \cdot 4$ & $22 \cdot 0$ & $31 \cdot 0$ & 21.9 \\
\hline $\begin{array}{l}\text { Heat production from } \\
\text { calorimetry (kcal/d) }\end{array}$ & 1802 & 2032 & 1850 & 1897 \\
\hline$T_{F}$ & $119 \cdot 9$ & $121 \cdot 3$ & $146 \cdot 7$ & $140 \cdot 8$ \\
\hline & $169 I \cdot I$ & $1922 \cdot 3$ & 1704 & 1757 \\
\hline$T$ & 1811 & 2044 & $185 \mathrm{I}$ & 1898 \\
\hline$T_{F / T}$ & 0.066 & 0.059 & 0.079 & 0.074 \\
\hline$T_{F} /$ Methane & 0.52 & 0.58 & 0.50 & 0.68 \\
\hline
\end{tabular}

$T_{F}$, heat produced during fermentation.

$T_{B}$, heat produced in the body.

$T$, total heat produced.

tion:energy lost as $\mathrm{CH}_{4}$ is approximately 0.5 . Similar calculations in Table 2 show that propanediol and versatic acids increase total heat production and decrease the proportion of heat produced in the rumen. They also show that the value for heat of fermentation: heat lost in $\mathrm{CH}_{4}$ may not be constant and that $\mathrm{CH}_{4}$ production might be a poor measurement for estimating heat of fermentation.

\section{DISCUSSION}

No assumptions are made in deriving equation nos. 7 and 8 , they are simply a consequence of the well-established Brouwer (1958) equations and partitioning of heat between the body and the rumen. 
We can substitute the values of $\alpha$ and $\beta$ obtained from stoichiometric relations into equation nos. 7 and 8 and obtain:

$$
\begin{aligned}
& T_{B}=4.74 \mathrm{I} \mathrm{O}-0.03 \mathrm{I} \mathrm{CO}_{2}-0.0236 P+0.002 \mathrm{CH}_{4}, \\
& \mathrm{~T}_{F}=-0.872 \mathrm{O}_{2}+\mathrm{I} .226 \mathrm{CO}_{2}+0.009 P-0.5 \mathrm{I} 7 \mathrm{CH}_{4} .
\end{aligned}
$$

If the values from Table $\mathrm{I}$ are substituted in equation nos. $\mathrm{I}_{5}$ and $\mathrm{I} 6$, the $\mathrm{CH}_{4}$ term contributes only $0.003 \%$ to the heat produced in the body and this can becertainly ignored. The protein term in equation no. I6 contributes $0.3 \%$; this is less than some of the errors involved in measurements and can be ignored too. These calculations can be taken as a justification for our logical arguments that $\mathrm{CH}_{4}$ production does not influence the heat produced in the animal body and that protein excretion does not influence the heat of fermentation in the rumen. They also confirm the accuracy of the Brouwer (1958) equations for a ruminant animal.

By using Bouwer's original calculation procedures it is possible to express $\alpha$ and $\beta$ in terms of specific respiratory constants (uptake of oxygen or output of carbon dioxide/unit weight of material completely oxidized) and in terms of heats of combustion of the main dietary components. These complex expressions tell us simply that the values of $\alpha$ and $\beta$ will remain constant if the composition of each component and consequently the equation that describes its combustion, remains unchanged.

The $\mathrm{CH}_{4}$ term in equation no. 8 does not imply any fixed relationship between $T_{\mathrm{F}}$ and $\mathrm{CH}_{4}$. On the other hand, if $\mathrm{O}_{2}$ and $\mathrm{CO}_{2}$ are kept constant, equation no. 16 shows that $T_{F}$ will vary inversely with $\mathrm{CH}_{4}$ and that the variation will be small. Under normal feeding conditions, both $T_{F}$ and $\mathrm{CH}_{4}$ will depend on the amount of food digested and this is more than anything else that suggested that $T_{F}$ and $\mathrm{CH}_{4}$ should be related. There are numerous fermentations in nature where no $\mathrm{CH}_{4}$ is produced. Yet, in these fermentations the substrates are converted to the usual end-products and the reactions are accompanied by heat production.

The author is grateful to Dr J. McLean for constructive criticism and advice.

\section{REFERENCES}

Blaxter, K. L. \& Martin, A. K. (1962). Br. J. Nutr. 16, 397.

Brouwer, E. (1958). Proc. 1st Symp. Energy Metab. (Copenhagen), p. 182.

Brouwer, E. (1965). In Energy Metabolism p. 44I. [K. L. Baxter, editor]. New York: Academic Press.

Clapperton, J. L. \& Czerkawski, J. W. (1971). Br. J. Nutr. 26, 459.

Clapperton, J. L. \& Czerkawski, J. W. (1972). Br. J. Nutr. 27, 553.

Czerkawski, J. W. (1978). J. Dairy Sci. 6I, 126I.

Czerkawski, J. W., Blaxter, K. L. \& Wainman, W. F. (1966). Br. J. Nutr. $20,495$.

Demeyer, D. \& Van Nevel, C. (1975). In Digestion and Metabolism in the Ruminant, p. 366 . [I. W. MacDonald and A. C. I. Warner, editors]. Armidale, New South Wales: The University of New England Publishing Unit.

Forbes, E. B., Kriss, M., Braman, W. W. \& French, R. B. (1927). J. Agric. res. 34, 865.

Houpt, T. R. (1968). Am. J. vet. Res. 29, 411.

Krogh, A. \& Schmit-Jensen, M. O. (1920). Biochem. J. 14, 686.

Marston, H. R. (1948). Biochem. J. 42, 564.

Webster, A. J. F. (1978). In Ruminant Digestion and Feed Evaluation, pp. 8.1-8.10 [D. F. Osbourn, D. E. Beever and D. J. Thomson, editors]. London: Agricultural Research Council. 